\title{
Duodenal Hematoma and Pancreatitis Complicating Endoscopic Intestinal Biopsy in a Boy with Noonan Syndrome
}

\author{
E. Leva*1, F. Macchini ${ }^{1}$, A. Di Cesare ${ }^{1}$, R. Arnoldi ${ }^{1}$, V. Gentilino ${ }^{1}$, G. Brisighelli ${ }^{1}$, G. Farris ${ }^{1}$, A. Morandi ${ }^{1}$, M. Torricelli ${ }^{1}$, Massimo Agosti ${ }^{2}$ and $^{1}$ \\ Eugenio Cocozza ${ }^{2}$
}

${ }^{1}$ Department of Pediatric Surgery, Fondazione IRCCS “Ca' Granda” - Ospedale Maggiore Policlinico, Milano, Italy

${ }^{2}$ Azienda Ospedaliera di Circolo, Varerse, Italy

\section{Summary}

Duodenal intramural hematoma is a rare condition, mostly described in children and young adults that can be a complication of duodenal biopsy, especially in patients with predisposing hemorrhagic diathesis. It can determine secondary pancreatitis because of ampullary hematoma. Noonan Syndrome (NS) is an autosomal dominant disorder characterized by short stature, typical facial dysmorphisms, congenital heart defects and other anomalies such as bleeding problems which have been reported in up to $55 \%$ of patients. We herein report a case of duodenal hematoma with pancreatitis developed after endoscopic biopsy in a boy who was initially suspected of having celiac disease on the base of his short stature and growth retardation. Afterwards a more careful past medical history collection and objective examination revealed characteristic features of NS which could have been picked-up in advance, thus avoiding an investigation, such as the duodenal endoscopic biopsy, which in NS patient is potentially more risky.

Keywords: Duodenal hematoma; Pancreatitis; Noonan syndrome; Children; Growth retardation

\section{Introduction}

Duodenal intramural hematoma is a rare condition, mostly described in children and young adults [1,2]. It can be a complication of duodenal biopsy, especially in patients with predisposing hemorrhagic diathesis $[3,4]$ and can determine secondary pancreatitis because of ampullary hematoma [1,2,5-7].

Noonan Syndrome (NS) is an autosomal dominant disorder characterized by short stature, typical facial dysmorphisms, congenital heart defects and other anomalies [8-10] such as bleeding problems which have been reported in up to $55 \%$ of patients [8-14]. NS is a clinical diagnosis.

\section{Case Report}

A 14 years old boy was transferred to our department for acute pancreatitis from a first level hospital. Three days before, multiple endoscopic duodenal biopsies were performed at the Department of General Gastroenterology of the hospital of origin, to rule out celiac disease because of unexplainable growth retardation and short stature. Previously, antigliadin and antiendomysium antibodies were recorded as border-line.

After the procedure he started complaining of epigastric pain for three days and emesis for the last day. His past medical history was positive for bilateral orchidopexy at 1 year of age, growth retardation treated with growth hormone (GH) for the last 8 years and a paediatric neuropsychiatric consultation for attention deficit. On examination he presented apirexial and stable vital signs but tender abdomen, painful over the epigastrium and right hypocondrium and absent bowel sounds. An ultrasound (US) scan showed an enlarged oedematous pancreas with heterogeneous echogenicity, a circumscribed heterogeneous duodenal parietal collection $(10 \times 5 \times 8 \mathrm{~cm})$ involving the second and third portions and some corpuscolated free fluid in peritoneal cavity. CT (computed tomography) scan confirmed and better defined those findings consisting with duodenal parietal hematoma conditioning an acute pancreatitis.
Vital signs were strictly monitored. Laboratory test showed increased serum amylase (1403 U/L) and lipase (1656 U/L) but normal full blood count, electrolites, liver and kidney functions. Full coagulation study was done, resulting in slightly increased PT and reduced levels of factors VII, X and factor V, while platelet aggregation and secretion resulted normal.

For this reason the patient received vitamin $\mathrm{K}$ and factor VII supplementation.

Conservative treatment was undertaken namely nasogastric drainage, absolute starving, total parenteral nutrition, somatostatin, analgesics, ranitidine and antibiotics. Follow-up with serial US scans showed a progressive regression of both the hematoma and the peritoneal fluid collection within a couple of weeks, confirmed by CT scan as well. Laboratory test showed regression of amylase and lipase values. Vital signs were stable throughout the recovery.

The patient was started on oral feeds at day 14 since initial diagnosis, stopped parenteral nutrition at day 20 and was discharged the day after on low fat diet.

During the recovery, a more accurate clinical evaluation of the patient have been collected: neonatal and infancy feeding difficulty with delayed weaning at 12 months, mild motor delay (sitting at 10 months, walking at 20 months, talking at 18 months), bilateral orchidopexy at 1 year of age, growth retardation with normal GH and low IGF-1, treated with GH for the last 8 years and, finally, a paediatric

*Corresponding author: Ernesto Leva, Department of Pediatric Surgery, Fondazione IRCCS "Ca' Granda" - Ospedale Maggiore Policlinico, Milano, Italy, E-mail: ernesto.leva@unimi.it

Received March 08, 2012; Accepted March 22, 2012; Published March 25, 2012

Citation: Leva E, Macchini F, Cesare AD, Arnoldi R, Gentilino V et al. (2012) Duodenal Hematoma and Pancreatitis Complicating Endoscopic Intestinal Biopsy in a Boy with Noonan Syndrome. J Trauma Treatment 1:122. doi:10.4172/ 2167-1222.1000122

Copyright: (c) 2012 Leva E, et al. This is an open-access article distributed under the terms of the Creative Commons Attribution License, which permits unrestricted use, distribution, and reproduction in any medium, provided the original author and source are credited. 
Citation: Leva E, Macchini F, Cesare AD, Arnoldi R, Gentilino V et al. (2012) Duodenal Hematoma and Pancreatitis Complicating Endoscopic Intestinal Biopsy in a Boy with Noonan Syndrome. J Trauma Treatment 1:122. doi:10.4172/2167-1222.1000122

neuropsychiatric consultation for attention deficit and behavioural problems (hyperactivity, fidgety, irritability).

Furthermore, a focused objective examination by the genetics team revealed characteristic features of NS, namely height of $140.5 \mathrm{~cm}$ (below $3^{\text {rd }}$ centile), wide internipple space (teletelia), and chest slightly excavatum, hypertelorism, triangular shaped face, down-slanting palpebral fissures.

Despite the genetic tests for NS resulted negative, the phenotypic features of the child confirmed the diagnosis.

Cardiac and ophthalmological evaluation, made to rule out some important anomalies associated to the syndrome, resulted normal (Figure 1)

A 1 month follow-up was unremarkable and the patient could start on free diet. Thereafter, no other problems were registered during the routine gastroenterologic follow-up.

\section{Discussion}

Noonan Syndrome is an autosomal dominant disorder characterized by short stature, typical facial dysmorphisms, congenital heart defects and other anomalies [8-10]. Its incidence is 1:1000-2500 live births [1322]. Approximately $50 \%$ of all NS patient have a mutation in the PTPN11 gene mapping on the long arm of chromosome 12 [23]. NS is a clinical diagnosis. There is great variability in expression and the phenotype changes significantly with time and becomes less pronounced with increasing age $[9,10,24]$. Facial features include hypertelorism, downslanting palpebral fissures, eyelid ptosis, a high arched palate; low set posteriorly rotated ears and short neck. During childhood the contour of the face becomes more triangular and coarse and chest deformities (pectus carinatum or excavatum, broad chest with wide internipple space) become significant $[9,13,22]$. In adolescent and young adult the neck appears webbed and nasolabial folds prominent. One third of NS patients have thick curly hair [8-10].

Weight and height are normal at birth but drop off below the $3^{\text {rd }}$ centile within the first few months. Average height is $162.5 \mathrm{~cm}$ in males and $152.7 \mathrm{~cm}$ in female [25]. The cause of it is not clear. Neonatal feeding difficulties and failure to thrive is present in $63 \%$ of patients, improving spontaneously later in infancy [13]. GH is usually normal whilst Insulin-like Growth Factor (IGF-1) is usually low. The majority of patients respond to GH treatment for a couple of years, then the velocity in growth diminishes again [26]. Over $80 \%$ of NS patient have a cardiac anomaly, pulmonary stenosis being the most common with hypertrophic cardiomyopathy [8-10,27]. Seventy seven percent of male NS patients have undescended testes at birth and the majority of them will require orchidopexy [8-10,28,29]. In both sexes pubertal

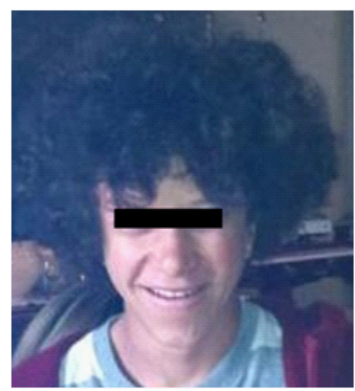

Figure 1: NS characteristic facial features of the patient. development is delayed. In most of children with NS demonstrate mild motor delay, partly attributed to muscle hypotonia $[9,10,13]$. Significant mental retardation is uncommon but some degree of learning and attention disability are rather frequent and may require special help in school [30]. Prominent behavioural problems are clumsiness, fidgety, irritability [31]. Eye anomalies, especially strabismus and refractive errors, are common. Coloboma is occasional [9,32]. Hearing loss can occur [8-10,33]. Lymphatic abnormalities are present in less than $20 \%$ of cases and hepatosplenomegaly in about $25 \%$ during childhood [810]. Easy bruising and bleeding problems have been reported in up to $55 \%$ of patients. Coagulation studies reveal prolonged bleeding time, factor VIII, XI and XII deficiencies, thrombocytopenia and platelet function defects [8-14]

In childhood, intramural hematoma of the duodenum usually results from trauma [15] but may also occur spontaneously in patients with bleeding disorders [3] or who are receiving anticoagulation therapy [4] and can be a rare complication of duodenal endoscopic biopsy [2] or therapeutic injection to bleeding ulcers [16] Anatomically, the relatively fixed retroperitoneal position of the third portion of duodenum and its adjacency to the lumbar spine make it more prone to shear injury when force is applied [17]. In addition, the rich submucosal vascular plexus and the lack of a serosal layer in the retroperitoneum may all increase the likelihood of bleeding [5].

Celiac disease is a common cause of growth retardation in children and its diagnosis is still based on multiple endoscopic duodenal biopsies [34-39].

In the reported clinical case, the duodenal hematoma and the secondary pancreatitis were consequence of a medical invasive procedure which seemed to be necessary to rule out celiac disease in a patient with short stature, growth retardation and levels of antigliadin and antiendomysium antibodies slowly higher than normal.

Postbiopsy duodenal hematoma has been reported mainly in children or young adults. The clinical symptoms of presentation are severe abdominal pain and emesis. Acute pancreatitis is frequently associated as consequence of parietal hematoma conditioning ampullary obstruction $[1,2,5,6,18]$. For this reason duodenal biopsy should be obtained as far from the papilla as possible [2]. The diagnosis of duodenal hematoma can be suspected on the base of upper gastro intestinal series [19] but is usually made on the base of ultrasound imaging and confirmed by CT scan $[17,20]$. The latter investigation allows demonstrating duodenal perforation, which would impose surgical treatment in order to avoid a significant increase in mortality [21]. In absence of perforation, in hemodinamically stable patients, a conservative management with nasogastric suction and parenteral hyperalimentation, is now recommended and can lead to resolution of all symptoms within $2-3$ weeks $[1,2,7]$, confirmed by US imaging and laboratory blood investigations.

As reported by Sgouros et al. [7], post-biopsy duodenal hematoma is a possible complication of duodenal endoscopic biopsies in Noonan syndrome. In the present experience, a hemorrhagic complication occurred in a young child without a previous diagnosis of coagulative disorders. A more detailed evaluation of his clinical features and of his past pathological history arose the suspicion of Noonan syndrome, lately confirmed.

A haematological study was conducted, that revealed a deficiency of factors V, VII and X, never previously reported in literature. These findings determined the necessity to provide a vitamin $\mathrm{K}$ and factor VII supplementation. Further molecular studies are at now in process 
Citation: Leva E, Macchini F, Cesare AD, Arnoldi R, Gentilino V et al. (2012) Duodenal Hematoma and Pancreatitis Complicating Endoscopic Intestinal Biopsy in a Boy with Noonan Syndrome. J Trauma Treatment 1:122. doi:10.4172/2167-1222.1000122

to determine the exact etiology of this correlation. A conservative treatment was sufficient to treat this child successfully.

The genetic tests for NS resulted negative in our patient, as expected since more than $50 \%$ of NS patients have no mutations of PTPN11 and other associated genes. Furthermore, the phenotypic features of the child were typical of NS confirming the diagnosis.

A focused objective examination on the patient revealed characteristic features of NS, namely height of $140.5 \mathrm{~cm}$ (below $3^{\text {rd }}$ centile), wide internipple space (teletelia), and chest slightly excavatum, hypertelorism, triangular shaped face, down-slanting palpebral fissures.

The present experience stresses the necessity of a correct clinical evaluation in case of hemorragic complications after diagnostic procedures in children not previously studied. In presence of specific malformations, NS has to be ruled out because it may represent a common cause of bleeding. An appropriate anamnesis and a general evaluation of the child can avoid significant complications.

\section{References}

1. Borsaru A, Nandurkar D (2007) Intramural duodenal haematoma presenting as a complication after endoscopic biopsy. Australas Radiol 51: 378-380.

2. Guzman C, Bousvaros A, Buonomo C, Nurko S (1998) Intraduodenal hematoma complicating intestinal biopsy: case reports and review of the literature. Am J Gastroenterol 93: 2547-2550.

3. DeRose JJ Jr, Diamond S, Bergman K (1997) Spontaneous duodenal hematoma in a patient with Glanzmann's thrombasthenia. J Pediatr Surg 32 : 1341-1343.

4. Gutstein DE, Rosenberg SJ (1997) Nontraumatic intramural hematoma of the duodenum complicating warfarin therapy. Mt Sinai J Med 64: 339-341.

5. Jones WR, Hardin WJ, Davis JT, Hardy JD (1971) Intramural hematoma of the duodenum: a review of the literature and case report. Ann Surg 173: 534-543.

6. Lloyd GM, Sutton CD, Marshall LJ, Jameson JS (2004) Case of duodenal haematoma treated with ultrasound guided drainage. ANZ J Surg 74: 500-103.

7. Sgouros SN, Karamanolis G, Papadopoulou E, Papageorgiou G, Stefanides G et al. (2004) Postbiopsy intramural hematoma of the duodenum in an adult with Noonan's syndrome. J Gastroenterol Hepatol 19: 1217-1219.

8. van der Burgt I (2007) Noonan syndrome. Orphanet J Rare Dis 2: 4

9. Noonan JA (1994) Noonan syndrome. An update and review for the primary pediatrician. Clin Pediatr (Phila) 33: 548-555

10. Noonan JA (2006) Noonan syndrome and related disorders: alterations in growth and puberty. Rev Endocr Metab Disord 7: 251-255.

11. Bertola DR, Carneiro JD, D'Amico EA, Kim CA, Albano LM, et al. (2003) Hematological findings in Noonan syndrome. Rev Hosp Clin Fac Med Sao Paulo 58: 5-8.

12. Massarano AA, Wood A, Tait RC, Stevens R, Super M (1996) Noonan syndrome: coagulation and clinical aspects. Acta Paediatr 85: 1181-1185.

13. Sharland M, Burch M, McKenna WM, Paton MA (1992) A clinical study of Noonan syndrome. Arch Dis Child 67: 178-183.

14. Witt DR, McGillivray BC, Allanson JE, Hughes HE, Hathaway WE, et al. (1988) Bleeding diathesis in Noonan syndrome: a common association. Am J Med Genet 31: 305-317.

15. Jewett TC Jr, Caldarola V, Karp MP, Allen JE, Cooney DR (1988) Intramura hematoma of the duodenum. Arch Surg 123: 54-58.

16. Sugai K, Kajiwara E, Mochizuki Y, Noma E, Nakashima J, et al. (2005) Intramura duodenal hematoma after endoscopic therapy for a bleeding duodenal ulcer in a patient with liver cirrhosis. Intern Med 44: 954-957.

17. Kunin JR, Korobkin M, Ellis JH, Francis IR, Kane NM, et al. (1993) Duodena injuries caused by blunt abdominal trauma: value of CT in differentiating perforation from hematoma. AJR Am J Roentgenol 160: 1221-1223.

18. Zinelis SA, Hershenson LM, Ennis MF, Boller M, Ismail-Beigi F (1989) Intramural haematoma following upper gastrointestinal endoscopic biopsy. Dig Dis Sci 34: 289-291.
19. Felson B, Levin EJ (1954) Intramural hematoma of the duodenum: a diagnostic roentgen sign. Radiology 63: 823-831.

20. Hayashi K, Futagawa S, Kozaki S, Hirao K, Hombo Z (1988) Ultrasound and CT diagnosis of intramural hematoma. Pediatr Radiol 18: 167-168.

21. Glazer GM, Buy JN, Moss AA, Goldberg HI, Federle MP (1981) CT detection of duodenal perforation. AJR Am J Roentgenol 137: 333-337.

22. Allanson JE (1987) Noonan syndrome. J Med Genet 24: 9-13.

23. Tartaglia M, Mehler EL, Goldberg R, Zampino G, Brunner HG, et al. (2001) Mutations in PTPN11, encoding the protein tyrosine phosphatase SHP-2, cause Noonan syndrome. Nat Genet 29: 465-468.

24. Allanson JE, Hall JG, Hughes HE, Preus M, Witt RD (1985) Noonan syndrome: the changing phenotype. Am J Med Genet 21: 507-514.

25. Ranke MB, Heidemann P, Knupfer C, Enders H, Schmaltz AA, et al. (1988) Noonan syndrome: growth and clinical manifestations in 144 cases. Eur J Pediatr 148: 220-227.

26. Limal JM, Parfait B, Cabrol S, Bonnet D, Leheup B, et al. (2006) Noonan syndrome: relationships between genotype, growth, and growth factors. J Clin Endocrinol Metab 91: 300-306

27. Marino B, Digilio MC, Toscano A, Giannotti A, Dallapiccola B (1999) Congenita heart diseases in children with Noonan syndrome: An expanded cardiac spectrum with high prevalence of atrioventricular canal. J Pediatr 135: 703-706.

28. Elsawi MM, Pryor JP, Klufio G, Barnes C, Patton MA (1994) Genital tract function in men with Noonan syndrome. J Med Genet 31: 468-470.

29. Theintz G, Savage MO (1982) Growth and pubertal development in five boys with Noonan's syndrome. Arch Dis Child 57: 13-17.

30. van der Burgt I, Thoonen G, Roosenboom N, Assman-Hulsmans C, Gabreels $\mathrm{F}$, et al. (1999) Patterns of cognitive functioning in school-aged children with Noonan syndrome associated with variability in phenotypic expression. J Pediatr 135: 707-713.

31. Lee DA, Portnoy S, Hill P, Gillberg C, Patton MA (2005) Psychological profile of children with Noonan syndrome. Dev Med Child Neurol 47: 35-38.

32. Reynolds DJ, Rubin SE, Fox J, Kodsi SR (2004) Ocular manifestations of Noonan syndrome in the pediatric patient. J AAPOS 8: 282-283.

33. Foster CA, Dyhrkopp PJ (1998) Noonan's syndrome with sensorineural hearing loss and vestibular abnormalities. Otolaryngol Head Neck Surg 119: 508-511.

34. Marsh MN (1993) Clinical and pathological spectrum of coeliac disease. Gut 34: 1740 .

35. Catassi C, Fasano A (2004) Celiac disease as a cause of growth retardation in childhood. Curr Opin Pediatr 16: 445-449.

36. Cárdenas A, Kelly CP (2002) Celiac sprue. Semin Gastrointest Dis 13: 232 244

37. Farrell RJ, Kelly CP (2002) Diagnosis of celiac sprue. Am J Gastroenterol 97 2679-2680.

38. Holtmeier W, Caspary WF (2006) Celiac disease. Orphanet J Rare Dis 1: 3.

39. Murray JA, Green PH (1999) Biopsy is the gold standard of diagnosis of celiac sprue. Gastroenterology 116: 1273-1274. 